\title{
Comparison of different Lewis acids supported on natural phosphate as new catalysts for chemoselective dithioacetalization of carbonyl compounds under solvent-free conditions
}

\author{
Mohamed Zahouily, ${ }^{a^{*}}$ Abdessamad Mezdar, ${ }^{\text {a }}$ Abdelhakim Elmakssoudi, ${ }^{\text {a }}$ Bahija Mounir ${ }^{\mathrm{a}}$, \\ Ahmed Rayadh ${ }^{a}$, Saïd Sebti ${ }^{b}$, and Hassan Bihi Lazrek ${ }^{c}$ \\ ${ }^{a}$ Laboratoire de Catalyse, Chimiométrie et Environnement, UFR de Chimie Appliquée, \\ Université Hassan II, Faculté des Sciences et Techniques, B. P. 146, 20650 Mohammadia,Maroc \\ ${ }^{b}$ Laboratoire de Chimie Organique, Catalyse et Environnement, Université Hassan II, Faculté \\ des Sciences Ben M'Sik, B.P. 7955, 20702 Casablanca, Maroc. \\ ${ }^{c}$ Laboratoire de Chimie Bioorganique, Faculté des Sciences Semlalia, B. P. S 15, Université \\ Cadi-Ayyad, Marrakech, Maroc \\ E-mail: mzahouily@yahoo.fr
}

\begin{abstract}
Various carbonyl compounds can be efficiently converted to their corresponding dithioacetals in the presence of catalytic amounts of $\mathrm{ZnCl}_{2}, \mathrm{NiCl}_{2}$ or $\mathrm{CuCl}_{2}$ supported on natural phosphate. The best catalytic activities were observed with the zinc catalysts. In addition, by employing these catalysts, highly chemoselective dithioacetalization of carbonyl compounds has been achieved.
\end{abstract}

Keywords: Carbonyl compounds, dithioacetals, dithiolanes, dithianes, chemoselective, natural phosphate

\section{Introduction}

The use of heterogeneous catalysts under solvent-free conditions is becoming very popular as it has many advantages: reduced pollution, reusability, high selectivity, low cost, and simplicity in process and in handling. These factors are especially important in industry.

Recently, an informative review ${ }^{1}$ by Toda et al. clearly pointed out the superiority of the solvent-free or the use of dry reaction conditions in chemical synthesis.

Thioacetalization of carbonyl compounds plays an important role in organic synthesis. Since the introduction of 1,3-dithianes as nucleophilic acylating reagents by Corey and $\mathrm{Seebach}^{2}$, dithioacetals have become widely used tools for $\mathrm{C}-\mathrm{C}$ bond formation. Furthermore, the stability exhibited by 1,3-dithiolanes under acidic and basic conditions has led to their synthetic utility as 
carbonyl protecting groups and as intermediates for the conversion of carbonyl compounds to their parent hydrocarbons ${ }^{3}$.

Recently, several acid catalysts have been used in the preparation of thioacetals such as $\mathrm{Zn}$ or $\mathrm{Mg}(\mathrm{OTf})_{2}{ }^{4}, \mathrm{BF}_{3} \cdot \mathrm{Et}_{2} \mathrm{O}^{5}, \mathrm{ZrCl}_{2} / \mathrm{SiO}_{2}{ }^{6}$, titanium tetrachloride ${ }^{7}, \mathrm{SOCl}_{2} / \mathrm{SiO}_{2}{ }^{8}, \mathrm{Zeolite}^{9}, \mathrm{WCl}_{2}{ }^{10}, 5$ $\mathrm{M} \mathrm{LiClO}_{4} / \mathrm{Et}_{2} \mathrm{O}(\mathrm{LPDE})^{11}, \mathrm{TaCl}_{5} / \mathrm{SiO}_{2}{ }^{12}, \mathrm{MoO}_{2}(\mathrm{acac})_{2}{ }^{13}$ and Yttrium triflate ${ }^{14}$ and other catalysts with more or less success ${ }^{15}$. Many of these methods require long reaction times and reflux temperatures and result in unwanted side reactions, whilst offering poor selectivity when applied to mixtures of aldehydes and ketones. Although some recent methods employing $\mathrm{LiBr}^{16}, \mathrm{InCl}_{3}{ }^{17}$, and $\mathrm{LiBF}_{4}{ }^{18}$ have been reported to show chemoselectivity, these Lewis acids are destroyed in the work-up procedure and cannot be recovered and reused.

On the other hand, we have used natural phosphate (NP) ${ }^{19}$ alone and doped as the new heterogeneous catalysts for several reactions such as Knœvenagel condensation ${ }^{20}$, construction of carbon-carbon ${ }^{21}$, carbon-sulfur ${ }^{22}$ and carbon-nitrogen ${ }^{23}$ bonds, epoxidation of alkenes ${ }^{24}$, Claisen-Schmidt condensation ${ }^{25}$ and synthesis of unsaturated arylsulfones ${ }^{26}$. NP has been used also as a Lewis acid catalyst or support in Friedel-Crafts alkylation ${ }^{27}$, 1,3-dipolar cycloaddition ${ }^{28}$ and acyclonucleoside synthesis ${ }^{29}$.

In continuation of our interest to develop environmentally safe methods, herein we wish to report an efficient method for the thioacetalization of carbonyl compounds in good to high yields, as well as the chemoselective protection of various carbonyl compounds by employing $\mathrm{ZnCl}_{2}$ supported on natural phosphate (Scheme 1, Table 1).

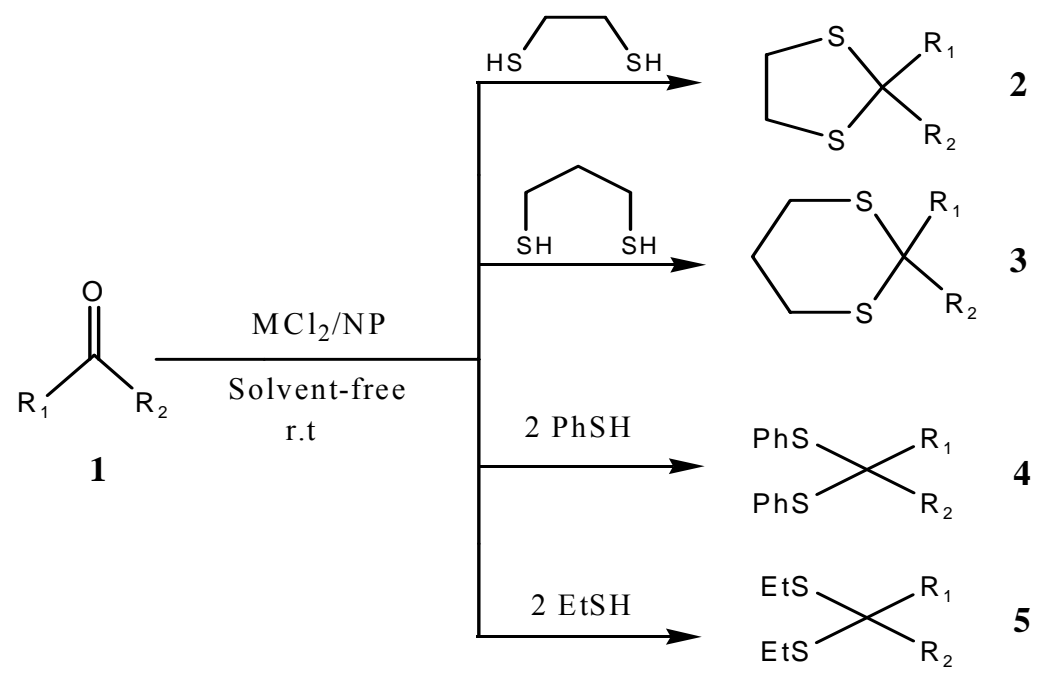

\section{Scheme 1}




\section{Experimental Section}

\section{Preparation of the catalyst and structural characteristics}

Natural phosphate (NP) used in this work was obtained in the Khouribga region (Morocco) ${ }^{19}$. Prior to use this material requires initial treatments such as crushing and washing. For use in organic synthesis, the NP is treated by techniques involving attrition, sifting, calcinations $\left(900^{\circ} \mathrm{C}\right)$, washing, and recalcination. These treatments lead to a fraction between 100 and $400 \mu \mathrm{m}$ that is rich in phosphate and has the following chemical composition $\mathrm{P}_{2} \mathrm{O}_{5}(34.24 \%), \mathrm{CaO}(54.12 \%), \mathrm{F}^{-}$ (3.37\%), $\mathrm{SiO}_{2}(2.42 \%), \mathrm{SO}_{3}(2.21 \%), \mathrm{CO}_{2}$ (1.13\%), $\mathrm{Na}_{2} \mathrm{O}(0.92 \%), \mathrm{MgO}(0.68 \%), \mathrm{Al}_{2} \mathrm{O}_{3}$ $(0.46 \%), \mathrm{Fe}_{2} \mathrm{O}_{3}(0.36 \%), \mathrm{K}_{2} \mathrm{O}(0.04 \%)$ and several metals $(\mathrm{Zn}, \mathrm{Cu}, \mathrm{Cd}, \mathrm{V}, \mathrm{U}, \mathrm{Cr})$ in the range of ppm. The structure of the material is similar to that of fluoroapatite $\left(\mathrm{Ca}_{10}\left(\mathrm{PO}_{4}\right)_{6} \mathrm{~F}_{2}\right)$. In sedimentary rocks, phosphates are formed from compounds derived from apatite by partial isomorphic substitution: $\mathrm{Ca}^{2+}$ ions by $\mathrm{Na}^{+}, \mathrm{Mg}^{2+}, \mathrm{Co}^{2+}, \mathrm{Fe}^{3+}$, or $\mathrm{Al}^{3+}, \mathrm{PO}_{4}{ }^{3-}$ ions by $\mathrm{VO}_{4}{ }^{3-}, \mathrm{SO}_{4}{ }^{2-}$, $\mathrm{CO}_{3}{ }^{2-}$ or $\mathrm{MnO}^{4-}$, and $\mathrm{F}^{-}$by $\mathrm{HO}^{-}$or $\mathrm{Cl}^{-}$. These different substitutions cause distortions of the structure which depends on the nature and the radii of the ions involved. This solid presented a very low surface area (BET) at $c a .1-1.43 \mathrm{~m}^{2} \mathrm{~g}^{-1}$.

The preparation of $\mathrm{MCl}_{2} / \mathrm{NP}(\mathrm{M}=\mathrm{Zn}, \mathrm{Cu}$ or $\mathrm{Ni})$ was as follows: $10 \mathrm{mmol}$ of $\mathrm{MCl}_{2}$ and $10 \mathrm{~g}$ of NP were mixed in $100 \mathrm{ml}$ of water and then evaporated to dryness and dried for $2 \mathrm{~h}$ at $150^{\circ} \mathrm{C}$ before use.

The modification of the apatite structure solid by $\mathrm{MCl}_{2}$ impregnation does not change the crystalline structure of the solid material [30]. It should be noted that no $\mathrm{MCl}_{2}$ phases were detected on the doped materials in all cases, indicating that $\mathrm{MCl}_{2}$ were highly dispersed in the solid material. Interestingly, some changes of structure of doped catalysts were observed in scanning electron micrographs (SEM). Thus, the comparaison of the images of $\mathrm{ZnCl}_{2} / \mathrm{NP}$ with NP (Figure 1) shows some modification in the particle morphology of doped materials. This result suggests that $\mathrm{ZnCl}_{2}$ interacted with the surface of NP. So, we can reasonably suspect that the modification of the surface morphology of the apatites was responsible for the enhancement of the catalytic activity observed with the doped materials.

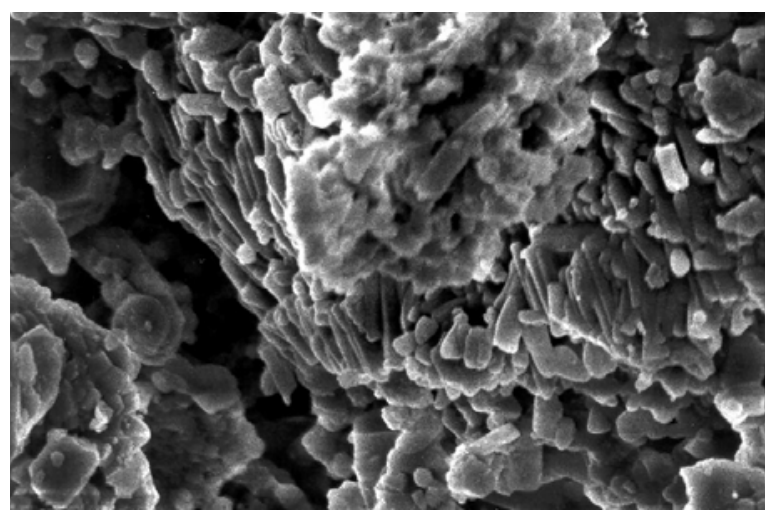

(a)

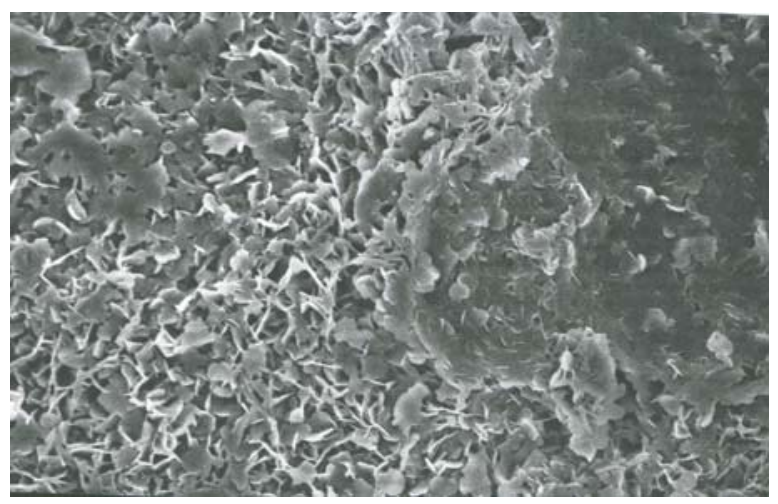

(b)

Figure 1. Scanning electron micrograph (SEM) images of (a) $\mathrm{NP}$ and (b) $\mathrm{ZnCl}_{2} / \mathrm{NP}$ 


\section{General procedure for the thioacetalization of carbonyl compounds}

To a freshly prepared catalyst $\mathrm{MCl}_{2} / \mathrm{NP}(0.3 \mathrm{~g})$ under stirring, a mixture of carbonyl compound 1 ( $2 \mathrm{mmol}$ ) and di- or mono-thiol ( 2.1 or $4.2 \mathrm{mmol}$, respectively) was added and the mixture was stirred until completion of the reaction, as monitored by thin layer chromatography (TLC). The reaction mixture was filtered and the catalyst washed with dichloromethane. After concentration of the filtrate under reduced pressure the residue was subjected to chromatography leading to the respective thioacetal ( 2 to 5 , Scheme 1, Table 1 ). The product structure was analysed by ${ }^{1} \mathrm{H},{ }^{13} \mathrm{C}$ NMR, IR spectrometry and melting points.

\section{Results and Discussion}

First of all, we have tested the natural phosphate alone $(0.1,0.3,0.5,0.7,1 \mathrm{~g})$ as the acidic catalyst in the thioacetalization of carbonyl compounds (Figure 2). Thus, various amount of NP alone have been used to catalyse the thioacetalization of $p$-chlorobenzaldehyde by thiophenol. A low yield of 4d was obtained with NP alone (Figure 2). The yields seem to be limited even if the time of the reaction is prolonged. However, the reaction time is very long (30 hours).

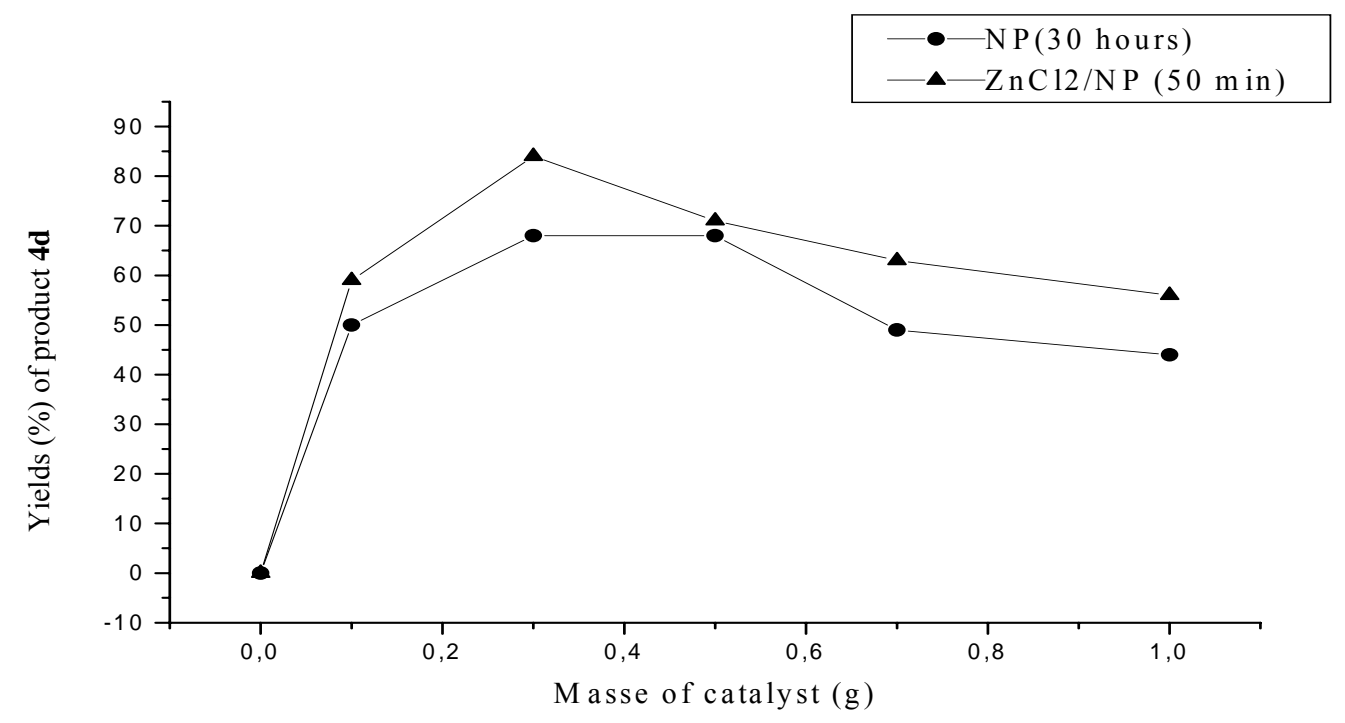

Figure 2. Weight effect of the catalyst NP alone and doped with $\mathrm{ZnCl}_{2}$ in the thioacetalization of p-chlorobenzaldehyde by thiophenol.

In view of the established beneficial effects of solid supports, we have investigated the use of the NP impregnated with metal halides for the thioacetalization of carbonyl compounds under mild conditions. These impregnation catalysts have been prepared as indicated before. 
Firstly, we have tested the NP impregnated with $\mathrm{ZnCl}_{2}$ as the solid catalyst for the thioacetalization of $p$-chlorobenzaldehyde by thiophenol. The best weight of $\mathrm{ZnCl}_{2} / \mathrm{NP}$ is $300 \mathrm{mg}$ (Figure 2). In a blank reaction in the presence of $40 \mathrm{mg}$ (quantity present in $\mathrm{ZnCl}_{2} / \mathrm{NP}$ catalyst) of $\mathrm{ZnCl}_{2}$ alone without NP the thioacetal $4 \mathbf{d}$ was obtained with low yields (25\%, $\left.70 \mathrm{~min}\right)$.

Furthermore, the metal halide effect was also examined. Thus, we have tested $\mathrm{CuCl}_{2}$ and $\mathrm{NiCl}_{2}$ alone and supported on NP. The thiocetalization of $p$-chloro benzaldehyde by thiophenol with $\mathrm{CuCl}_{2}, \mathrm{CuCl}_{2} / \mathrm{NP}, \mathrm{NiCl}_{2}$ and $\mathrm{NiCl}_{2} / \mathrm{NP}$ are $21,83,18$, and 40 , respectively, after 70 min of reaction time. The results obtained with product $\mathbf{4 d}$ using impregnated catalysts are regrouped in Figure 3. Among these catalysts, satisfactory results have been obtained with $\mathrm{ZnCl}_{2}$ supported on the NP. The NP was the preferred choice as support to keep the reaction medium under mild and neutral conditions (Figure 3).

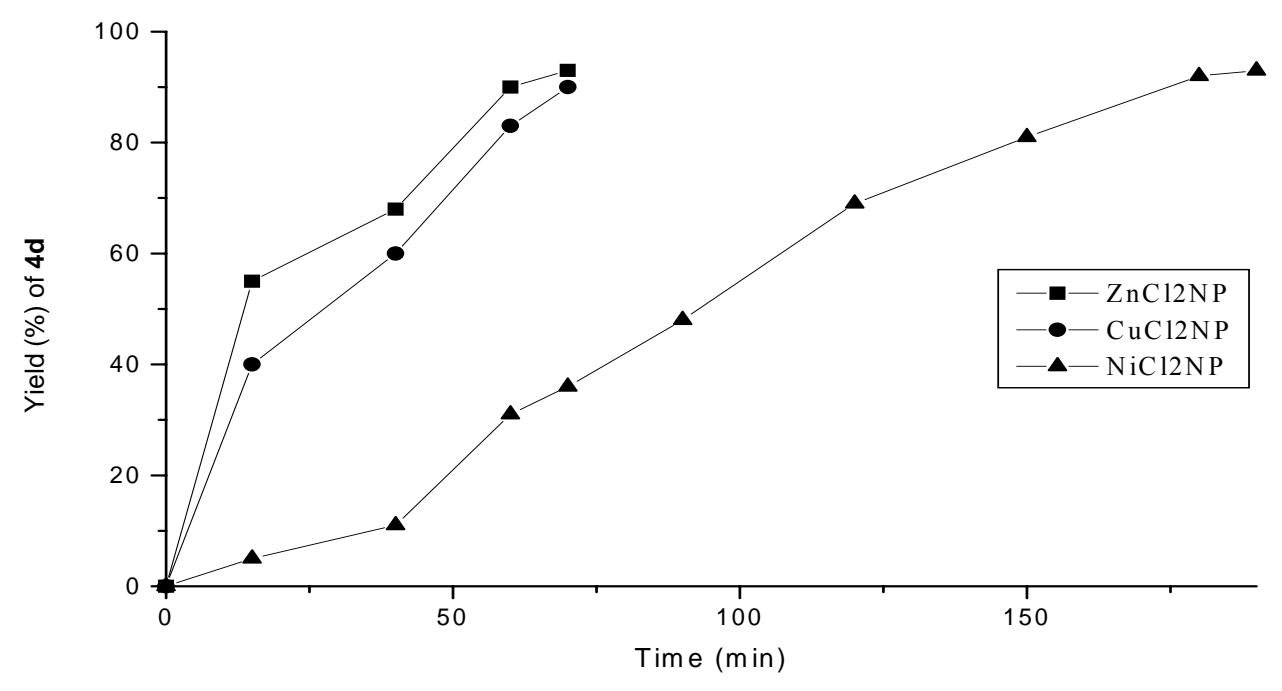

Figure 3. Kinetic curves of product $4 \mathrm{~d}$ synthesis catalysed by $\mathrm{ZnCl}_{2} / \mathrm{NP}, \mathrm{CuCl}_{2} / \mathrm{NP}$ and $\mathrm{NiCl}_{2} / \mathrm{NP}$.

The best conditions for the thioacetalization of $p$-chlorobenzaldehyde by thiophenol are generalized to other carbonyl compounds. Accordingly, dithioacetals and 1,3-dithiolanes have been obtained by the reaction of thiols (ethanethiol and thiophenol) and dithiols (1,2ethanedithiol, 1,2-propanedithiol), respectively, in the presence of catalytic amounts of $\mathrm{ZnCl}_{2} / \mathrm{NP}$ (Scheme 1); the results are illustrated in Table 1. 
Table 1. $\mathrm{ZnCl}_{2} / \mathrm{NP}$ catalysed protection of carbonyl compounds as dithioacetals, 1,3-dithiolanes and 1,3-dithianes

\begin{tabular}{|c|c|c|c|c|}
\hline Entry & Products & Substrate & Reagent & $\begin{array}{c}\text { Yield } / \% \\
{\text { (time } / \mathrm{min})^{\mathrm{a}}}\end{array}$ \\
\hline 1 & $2 \mathrm{a}$ & Benzaldehyde & $\mathrm{HS}\left(\mathrm{CH}_{2}\right)_{2} \mathrm{SH}$ & $91(25)$ \\
\hline 2 & $2 \mathbf{b}$ & p-Methoxybenzaldehyde & $\mathrm{HS}\left(\mathrm{CH}_{2}\right)_{2} \mathrm{SH}$ & $94(20)$ \\
\hline 3 & $2 c$ & p-Methylbenzaldehyde & $\mathrm{HS}\left(\mathrm{CH}_{2}\right)_{2} \mathrm{SH}$ & $93(25)$ \\
\hline 4 & 2d & p-Chlorobenzaldehyde & $\mathrm{HS}\left(\mathrm{CH}_{2}\right)_{2} \mathrm{SH}$ & $89(25)$ \\
\hline 5 & $2 \mathbf{e}$ & $p$-Nitrobenzaldehyde & $\mathrm{HS}\left(\mathrm{CH}_{2}\right)_{2} \mathrm{SH}$ & $87(35)$ \\
\hline 6 & $2 f$ & Acetophenone & $\mathrm{HS}\left(\mathrm{CH}_{2}\right)_{2} \mathrm{SH}$ & $85(75)$ \\
\hline 7 & $2 g$ & Cyclohexanone & $\mathrm{HS}\left(\mathrm{CH}_{2}\right)_{2} \mathrm{SH}$ & $89(60)$ \\
\hline 8 & $2 \mathbf{h}$ & Cinnamaldehyde & $\mathrm{HS}\left(\mathrm{CH}_{2}\right)_{2} \mathrm{SH}$ & $92(25)$ \\
\hline 9 & 3a & Benzaldehyde & $\mathrm{HS}\left(\mathrm{CH}_{2}\right)_{3} \mathrm{SH}$ & $89(25)$ \\
\hline 10 & $3 \mathbf{b}$ & p-Methoxybenzaldehyde & $\mathrm{HS}\left(\mathrm{CH}_{2}\right)_{3} \mathrm{SH}$ & $96(25)$ \\
\hline 11 & $3 c$ & p-Methylbenzaldehyde & $\mathrm{HS}\left(\mathrm{CH}_{2}\right)_{3} \mathrm{SH}$ & $90(25)$ \\
\hline 12 & 3d & p-Chlorobenzaldehyde & $\mathrm{HS}\left(\mathrm{CH}_{2}\right)_{3} \mathrm{SH}$ & $92(30)$ \\
\hline 13 & $3 \mathbf{e}$ & $p$-Nitrobenzaldehyde & $\mathrm{HS}\left(\mathrm{CH}_{2}\right)_{3} \mathrm{SH}$ & $91(40)$ \\
\hline 14 & $3 f$ & Acetophenone & $\mathrm{HS}\left(\mathrm{CH}_{2}\right)_{3} \mathrm{SH}$ & $78(75)$ \\
\hline 15 & $3 g$ & Cyclohexanone & $\mathrm{HS}\left(\mathrm{CH}_{2}\right)_{3} \mathrm{SH}$ & $80(60)$ \\
\hline 16 & $4 a$ & Benzaldehyde & $\mathrm{PhSH}$ & $71(20), 90(40)$ \\
\hline 17 & $4 b$ & p-Methoxybenzaldehyde & $\mathrm{PhSH}$ & $80(20), 94(35)$ \\
\hline 18 & $4 c$ & p-Methylbenzaldehyde & $\mathrm{PhSH}$ & $76(20), 90(40)$ \\
\hline 19 & 4d & p-Chlorobenzaldehyde & $\mathrm{PhSH}$ & $55(20), 93(70)$ \\
\hline 20 & $4 e$ & $p$-Nitrobenzaldehyde & $\mathrm{PhSH}$ & $40(20), 88(55)$ \\
\hline 21 & $4 f$ & Acetophenone & $\mathrm{PhSH}$ & $91(90)$ \\
\hline 22 & $4 g$ & Cyclohexanone & $\mathrm{PhSH}$ & $87(60)$ \\
\hline 23 & $4 h$ & Acetone & $\mathrm{PhSH}$ & $91^{\mathrm{b}}-(60)$ \\
\hline 24 & $5 a$ & Benzaldehyde & EtSH & $90-(30)$ \\
\hline 25 & $5 \mathbf{b}$ & p-Methoxybenzaldehyde & EtSH & $93-(25)$ \\
\hline 26 & $5 c$ & $p$-Methylbenzaldehyde & EtSH & $92-(30)$ \\
\hline 27 & $5 d$ & p-Chlorobenzaldehyde & EtSH & $88-(40)$ \\
\hline 28 & $5 e$ & $p$-Nitrobenzaldehyde & EtSH & $85-(45)$ \\
\hline 29 & $5 f$ & Cyclohexanone & EtSH & $90-(60)$ \\
\hline
\end{tabular}

${ }^{a}$ Yields refer to isolated in pure products.

${ }^{b}$ Yields based on thiol as reagent, as the acetone is volatile. 
Because the conversion of aldehydes is faster than that of ketones, as shown in Table 1 , the present method can be used for the chemoselective protection of aldehydes in the presence of a ketone function [31]. For example, when an equimolar mixture of aldehyde and ketone was allowed to react with 1,2-ethanedithiol in the presence of a catalytic amount of $\mathrm{ZnCl}_{2} / \mathrm{NP}$, only the 1,2-dithiane derivative of the corresponding aldehyde was obtained; ketone was recovered quantitatively (Scheme 2). Furthermore, the thioacetalization of ethyl acetoacetate also exhibited splendid selectivity towards the acetyl group (Scheme 2). In addition, this method is free from the problem of Michael addition encountered in some cases of $\alpha, \beta$-unsaturated systems with some reagents [32] (entry 8, Table 1).

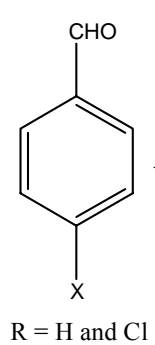<smiles>CC(=O)c1ccccc1</smiles>
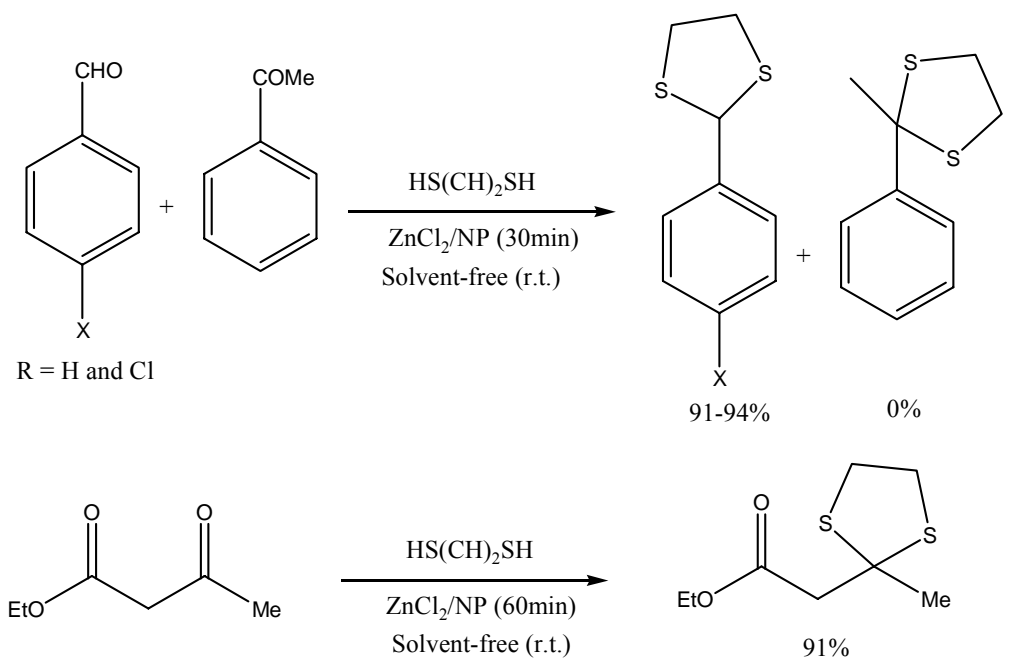

\section{Scheme 2}

To evaluate the effect of the presence of an electron acceptor or donor on the aromatic ring of benzaldehyde, the reaction was carried out between thiophenol and substituted benzaldehyde derivatives using $\mathrm{ZnCl}_{2} / \mathrm{NP}$ as catalyst (Scheme 1). Results in Table 1 show that the presence of electron-withdrawing groups on the aromatic ring of the aldehydes (entry 19-20, Table 1) decreases the yields proportionally to the value of Hammet constant. Meanwhile, the presence of electron-donating groups (entry 16-18, Table 1) increases the yields, demonstrating the participation of both the aldehydes and the thiol in the rate controlling step of the reaction. The activity of $\mathrm{ZnCl}_{2} / \mathrm{NP}$ seems to be higher than other known catalysts (Table 2). 
Table 2 Comparison of $\mathrm{ZnCL}_{2} / \mathrm{NP}$ with several heterogeneous homogeneous catalysts in the synthesis of products $3 \mathbf{a}$ and $\mathbf{3 g}$

\begin{tabular}{|c|c|c|c|}
\hline \multirow[t]{2}{*}{ Entry } & \multirow[t]{2}{*}{ Solid catalyst } & \multicolumn{2}{|c|}{ Yields(time) $[(\%)(\text { time} / \mathrm{min})]^{\mathrm{a}}$} \\
\hline & & Product $3 \mathrm{a}$ & Product $3 g$ \\
\hline 1 & $\mathrm{ZnCl}_{2} / \mathrm{NP}$ & $89(25)$ & $78(75)$ \\
\hline 2 & NP & $44(1440)^{b}$ & --- \\
\hline 3 & $\mathrm{I}_{2} / \mathrm{NP}[33]$ & $93(4)$ & $87(20)$ \\
\hline 5 & $\mathrm{Se}(\mathrm{OTf})_{3}[15 \mathrm{~b}]$ & $94(30)$ & --- \\
\hline 6 & $\mathrm{Y}(\mathrm{OTf})_{3}[14]$ & $89(45)$ & $87(360)$ \\
\hline 7 & $\mathrm{CoCl}_{3}[15 \mathrm{c}]$ & $91(60)$ & -- \\
\hline 8 & Zeolite-HY [11] & $96(60)$ & $87(60)$ \\
\hline 9 & Zeolite-CaY [11] & $91(60)$ & $89(60)$ \\
\hline 10 & Zeolite-MgY [11] & $86(60)$ & $80(60)$ \\
\hline 11 & $\mathrm{MoO}_{2}(\mathrm{acac})_{2}[13]$ & $94(180)$ & $85(180)$ \\
\hline 12 & $\mathrm{Li}(\mathrm{OTf})_{3}[15 \mathrm{~d}]$ & $99(5)^{\mathrm{c}}$ & $96(35)^{c}$ \\
\hline
\end{tabular}

${ }^{\mathrm{a}}$ Yields refer to isolated and chromatographically pure compounds; ${ }^{\mathrm{b}}$ Reaction carried out solventfree conditions; ${ }^{c}$ Reaction carried at $90-110^{\circ} \mathrm{C}$.

\section{Conclusions}

We have developed a simple and efficient method for the chemoselective protection of carbonyl compounds as dithioacetals, dithiolanes and dithianes using a catalytic amount of a Lewis acid supported on natural phosphate in solvent-free conditions at room temperature. Further, the natural phosphate of non-toxic and inexpensive catalysts can be readily recovered and reused, thus making this procedure more environmentally acceptable.

\section{References and notes}

1. Tanaka, K.; Toda, F. Chem, Rev. 2000, 100, 1025.

2. (a) Corey, E. J.; Seebach, D. J. Org. Chem. 1966, 31, 4097; (b) Seebach, D. Synthesis 1969, 17; (c) Groebel, B. T.; Seebach, D. Synthesis 1977, 357; (d) Seebach, D. Angew. Chem.Int., Ed.. 1979, 18, 239.

3. (a) Greene, T. W. Protective Groups in Organic Synthesis, John Wiley, New York, 1981,pp. 129-133; (b) Yus, M.; Nájera, C.; Foubelo, F. Tetrahedron 2003, 59, 6147; (c) Sartori, G.; Ballini, R.; Biji, F.; Bosica, G.; Maggi, R.; Righi, P. Chem. Rev. 2004, 104, 199.

4. Corey, E. J.; Shimoji, K. Tetrahedron Lett. 1983, 24, 169. 
5. (a) Fieser, L. F. J. Am. Chem. Soc., 1954, 76, 1945; (b) Nakata, T.; Nagao, S.; Mori, S.; Oishi,T. Tetrahedron Lett. 1985, 26, 6461.

6. Pentey, H. K.; Margan, S. Tetrahedron Lett. 1996, 37, 4621.

7. Kumar, V.; Dev, S. Tetrahedron Lett. 1983, 24, 1289.

8. Kamitori, Y.; Hojo, M.; Masuda, R.; Kimura, T.; Yoshida, T. J. Org. Chem. 1986, 52, 1427.

9. Latitha, A.; Pitchumani, K.; Srinivasan, C. Green Chemistry 1999, 175.

10. Firouzabadi, H.; Iranpoor, N.; Karimi, B. Synlett 1998, 739.

11. Geetha Saraswathy, V.; Sankararaman, S. J. Org. Chem. 1994, 59, 4665.

12. Chandrasekhar, S.; Takhi, M.; Reddy, Y. R.; Mohapatra, S.; Rao, C. R.; Reddy, K. V. Tetrahedron 1977, 53, 14997.

13. Rana, K. K.; Guin, C.; Jana, S.; Roy, S. C. Tetrahedron Lett. 2003, 44, 8597.

14. Kanta De, S. Tetrahedron Lett. 2004, 45, 2339.

15. (a) Kamal, A.; Chouhan., G. Tetrahedron Lett. 2002, 43, 1347; (b) Kanta De, S. Tetrahedron Lett. 2004, 45, 1035; (c) Firouzabadi, H.; Karimi, B.; Eslami, S. Tetrahedron Lett. 1999, 40, 4055; (d) Muthusamy, S.; Arulananda Babu, S.; Gunanathan, C. Tetrahedron 2002, 58, 7897; (e) Shinde, Borate, H. B.; Wakharkar, R. D. Arkivoc 2004, 14, 110.

16. Firouzabadi, H.; Iranpoor, N.; Karimi, B. Synthesis 1999, 58.

17. Muthusamy, S.; Arulananda Babu, S.; Gunanathan, C. Tetrahedron Lett. 2001, 42, 359.

18. Yadav, J. S.; Reddy, B. V. S.; Pandey, S. K. Synlett 2001, 238.

19. Natural phosphate (NP) comes Khouribga region (Morocco). It is readily available (raw or treated) from CERPHOS 37, Bd My Ismail, Casablanca, Morocco.

20. (a) Sebti, S.; Smahi, A.; Solhy, A. Tetrahedron Lett. 2002, 43, 1813; (b) Zahouily, M.; Bahlaouan, B.; Solhy, A.; Sebti, S. React. Kinet. Catal. Lett. 2003, 78, 129.

21. Zahouily, M.; Bahlaouan, B.; Aadil, M.; Rayadh, A.; Sebti, S. Org. Process Research \& Development 2004, 8, 275.

22. Abrouki, Y.; Zahouily, M.; Rayadh, A.; Bahlaouan, B.; Sebti, S. Tetrahedron Lett. 2002, 43, 8951.

23. (a) Zahouily, M.; Bahlaouan, B.; Rayadh, A.; Sebti, S. Tetrahedron Lett. 2004, 45, 4135; (b) Zahouily, M.; Bahlaouan, O.; Bahlaouan, B.; Rayadh, A.; Sebti, S. Arkivoc 2005, 13, 150.

24. Fraile, J. M.; Garcia, J. I.; Mayoral, J. A.; Sebti, S.; Tahir, R. Green Chem. 2001, 3, 271.

25. Sebti, S.; Solhy, A.; Tahir, R.; Boulaajaj, S.; Mayoral, J. A.; Fraile, J. M.; Kossir, A.; Oumimoun, H. Tetrahedron Lett. 2001, 42, 7953.

26. Zahouily, M.; Salah, M.; Bahlaouan, B.; Rayadh, A.; Houmam, A.; Hamed, E. A.; Sebti, S. Tetrahedron 2004, 60, 1631.

27. Sebti, S.; Rhihil, A.; Saber, A. Chem. Lett. 1996, 8, 721.

28. Lazrek, H. B.; Rochdi, A.; Kabbaj, Y.; Taourirte, M.; Sebti, S. Synth. Commun. 1999, 29, 1057.

29. Alahiane, A.; Rochdi, A.; Taourirte, M.; Redwane, N.; Sebti, S.; Lazrek, H. B. Tetrahedron Lett. 2001, 42, 3579. 
30. Saber, A.; Smahi, A.; Solhy, A.; Nazih, R.; Elaabar, B.; Maizi, M.; Sebti, S. J. Mol. Catal. A: Chemical 2003, 202, 229

31. Only a few methods are known in the literature for the chemoselective protection of aldehydes in the presence of ketone: ref. 15a and references cited therein.

32. Corey, E. J.; Shimoji, K. Tetrahedron Lett. 1983, 24, 169.

33. Zahouily, M.; Mezdar, A.; Rakik, J.; Elmakssoudi, A.; Rayadh, A.; Sebti, S. J. Mol. Catal. A: Chemical 2005, 233, 43. 